\title{
THE END OF THE
}

\section{CHINESE 'MIDDLE AGES'}

Essays in Mid-Tang

Literary Culture 



\title{
THE END OF THE CHINESE 'MIDDLE AGES'
}

\author{
Essays in Mid-Tang \\ Literary Culture
}

\author{
Stephen Owen
}

Stanford University Press

Stanford, California 


\section{ISBN: 9780804726665 \\ ISBN: 9780804726672}

Stanford University Press

Stanford, California

(C) 1996 by the Board of Trustees of the

Leland Stanford Junior University

Printed in the United States of America

CIP data appear at the end of the book

Stanford University Press publications are distributed exclusively by Stanford University Press within the United States, Canada, Mexico, and Central America; they are distributed exclusively by Cambridge University Press throughout the rest of the world. 